\title{
Vitamin D Deficiency is Associated with Anemia, Cardiovascular Risk, and Lifestyle
}

\author{
Hawro D. Ismael', Goran Q. Othman',3, Azad H. Amin², Jabbar H. Odey², Badraddin Umar Abdullah", \\ Hashem H. Abdulla ${ }^{5}$, Layla A. Kareem ${ }^{1}$, Hataw J. Taher ${ }^{1}$ \\ ${ }^{1}$ Department of Medical Lab. Technology, Health Technical College, Erbil Polytechnic University, Erbil, Kurdistan Region, Iraq, ${ }^{2}$ Department of \\ Medical Lab. Technology, Soran Technical Institute, Erbil Polytechnic University, Erbil, Kurdistan Region, Iraq, ${ }^{3}$ Department of Medical Lab. \\ Technology, Al-Qalam University College, Kirkuk, Iraq, ${ }^{4}$ Department of Biology, College of Education/Shaqlawa, Salahaddin University, Erbil, \\ Kurdistan Region, Iraq, ${ }^{5}$ Department of Nursing, Shaqlawa Technical College, Erbil Polytechnic University, Erbil, Kurdistan Region, Iraq
}

\section{*Corresponding author: Goran Q. Othman, \\ Department of Medical Lab. Technology, Soran Technical Institute, Erbil Polytechnic University, Erbil, Kurdistan Region, Iraq. \\ E-mail: goran.othman@epu. edu.iq}

Received: 15-02-2020

Accepted: 11-05-2021

Published: 30-06-2021

DOI

10.25156/pti.v11n1y2021.pp134-138

\section{A B S T R A C T}

Traditionally, Vitamin D has been associated primarily with bone health, while further investigations revealed that a sufficient amount is important for many organ functions. Data of 314 individuals were obtained from Erbil governorate public and private hospitals from patients admitted to there for testing their level of Vitamin D and other tests according to their doctor's prescription. The variable related to their lifestyle, metabolic syndrome, and hematology evaluations were obtained. The body mass index, number of sleeping hours, number of hours spent with electronic devices, serum lipid level anemia-related tests were measured. The results showed that serum $25(\mathrm{OH})$ Vitamin D levels in studied individuals were related to hyperlipidemia serum cholesterol measures. The level of Vitamin B12 and Iron status were lower in the Vitamin D deficiency (VDD) individuals. Mean platelet volume was higher in vitamin-deficient patients which induces the risk of cardiovascular (CV) diseases. This finding suggests the relation between VDD and metabolic syndrome, CV, and anemia-related measurement.

Keywords: Vitamin D deficiency; Anemia; Lifestyle; Hematology

\section{INTRODUCTION}

Vitamin D deficiency (VDD) is an important public health problem in both developed and developing countries, with a reported worldwide prevalence of $30-80 \%$ in children and adults. This worldwide pandemic generally remains unrecognized and untreated (Calvo et al., 2005). The role of 25(OH)D in bone mineralization is well-documented. However, numerous recent studies have reported a link between $25(\mathrm{OH}) \mathrm{D}$ deficiency and several chronic disorders, such as type 1 diabetes mellitus, cardiovascular disease (CVD), and several malignancies (Holick, 2007).

It has been observed that VDD is associated with sleep apnea and sleep duration, however, there is conflicting data from intervention trials on the effect of Vitamin $\mathrm{D}$ supplementation on sleep quality in men and women (Liu et al., 2020).

It has been known that adequate Vitamin D status is important for the optimal function of many organs and tissues throughout the body, including the CV system (Oren et al., 2010, Bell et al., 1985).
Vitamin D is a steroid hormone that can act on cellular differentiation and growth in the bone marrow. 25-Hydroxyvitamin D (25OHD) may play a role in modulating cell development processes such as hematopoiesis and lymphocyte differentiation (Santoro et al., 2015, Riccio et al., 2015, Sooragonda et al., 2015). Thus, VDD may have an adverse effect on the red blood cell erythropoiesis in the bone marrow and partially explain the high incidence of iron deficiency anemia and recurrent infections in children with VDD. Vitamin D insufficiency has also been linked to hypertension and CV events in observational studies (Golbahar et al., 2013).

Recent evidence suggests that other dietary factors, such as adequate Vitamin D consumption, may affect iron regulation and erythropoiesis (Atkinson et al., 2014). Although previous reports suggest that serum 25OHD, which is widely regarded as the best marker of total body Vitamin D status, is associated with hemoglobin levels, these studies either had limited sample sizes, or were primarily focused on children, the elderly, only women, or adults in a healthcare setting (Hirani et al., 2015).

Despite our understanding of how to prevent and treat traditional CV risk factors, CVD remains the leading cause 
of death of both men and women in the US (Wang et al., 2012). Thus, there is widespread interest in a number of emerging nontraditional risk factors for the detection of early CVD in order to implement aggressive preventive therapies. 25OHD deficiency has been identified as a potential novel CVD risk factor (Semple and Freedman, 2010).

Over the past few decades, considerable numbers of studies have investigated the associations between Vitamin D level, platelet count, and mean platelet volume (MPV) with several diseases. Both VDD and elevated MPV are associated with increased rate or risk of coronary artery disease, stroke, metabolic syndrome, obesity, hypertension, and type 2 diabetes (Rondina et al., 2013, Jaumdally et al., 2007), decreased Vitamin D levels are associated with critical CV risk factors, such as arterial hypertension, diabetes mellitus, and dyslipidemia, which are the prognosticators of the severe CVD, including strokes and infarctions (Podzolkov et al., 2018). but few attempts have been made to determine the relationship between Vitamin D and MPV (Valettas and Herrmann, 2003). Here, we investigated the relationship between changes in MPV and other related variables and vitamin $\mathrm{D}$ levels in Soran district population.

Positive associations between $25(\mathrm{OH}) \mathrm{D}$ deficiency and the prevalence of obesity have been shown. Studies in the adult population suggested that adequate serum $25(\mathrm{OH})$ $\mathrm{D}$ levels could be connected with increased adipocyte activity and oxidation of fat, as well as the potential for improving insulin sensitivity, which can lead to weight loss (Parikh et al., 2004).

This project aims to find out the association of $25 \mathrm{OHD}$ levels and the risk of CVD, hematological abnormalities, lifestyle, and the measurements related to metabolic syndrome beginning from body mass index (BMI) to serum Lipid profile levels.

\section{MATERIALS AND METHODS}

\section{Subjects and Patients}

Prospective data of 314 individuals were obtained from the Erbil governate public and private hospitals from patients admitted to there for testing their level of Vitamin D and other tests according to their doctor's prescription. The data collected from November 2019 to February 2020.

A questionnaire form (Table 1) was prepared for data collection. The questions focused on general demographic characteristics and lifestyles besides their clinical conditions.

\section{Laboratory Measurements}

According to the cases, the laboratory tests results were obtained from the patients after taking their questionnaire answers. We gave code number to all patients, and the same codes were given to the test results.

The variable related to their lifestyle and metabolic syndrome-related laboratory evaluations were obtained. The BMI, number of sleeping hours, number of hours spent with electronic devices, serum lipid level were measured for most of the patients.

\section{Data Analysis}

The data were then added to a master sheet created by Excel program to be ready for statistical analysis by Graph pad prism (Version 8.0). The analysis was performed applying one-way ANOVA and correlation coefficient. All data were presented as mean and standard error, and all figures were created by Graph pad prism program.

\section{RESULTS AND DISCUSSION}

Current results indicated that lifestyle managements are strongly related to the level of Vitamin D in serum, or

Table 1: The study questionnaire form for prospective data collection

\begin{tabular}{|c|c|c|c|c|}
\hline \multicolumn{5}{|c|}{ Patients code } \\
\hline Gender & Male & \multicolumn{3}{|c|}{ Female } \\
\hline Age & \multicolumn{4}{|c|}{ ( )Years } \\
\hline Time mobile & \multicolumn{4}{|c|}{$3-6 h=2$} \\
\hline Weight & \multicolumn{4}{|c|}{ ( ) Kg } \\
\hline Hight & \multirow{2}{*}{\multicolumn{4}{|c|}{$\begin{array}{c}(\mathrm{cm} \\
\left(\text { Weight/Length }(\mathrm{m})^{2}\right)\end{array}$}} \\
\hline body mass index & & & & \\
\hline Sleep time duration & $<5 \mathrm{~h}=1$ & $5-6 h=2$ & $6-8 h=3$ & $\begin{array}{l}>8 \\
h=4\end{array}$ \\
\hline Chronic disease & Yes & & No & \\
\hline
\end{tabular}
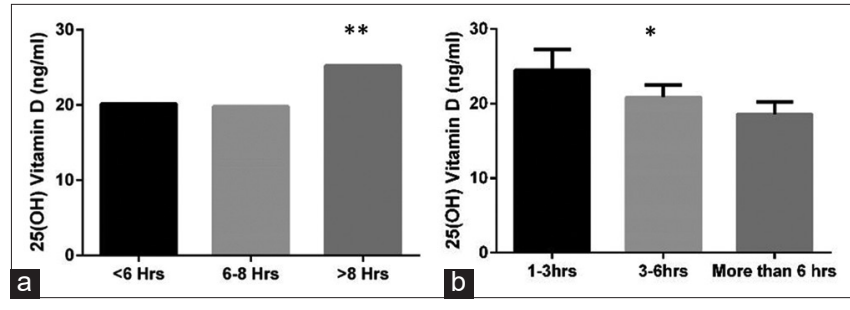

Figure 1: Serum 25(OH) Vitamin D level in studied individuals according to their lifestyle including their (a) number of sleeping hours and (b) the number of hours they spent with electronic devices. All data are expressed as Mean \pm SE

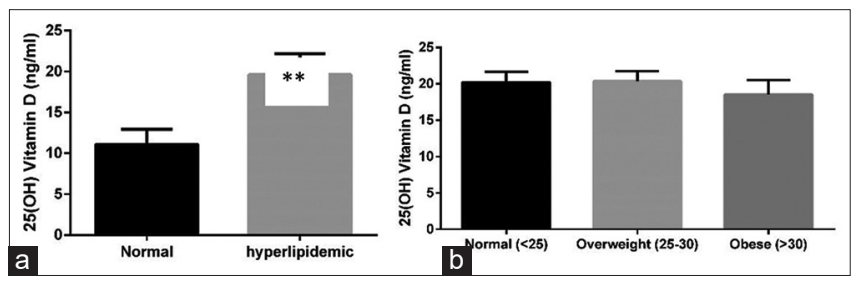

Figure 2: Serum 25(OH) Vitamin D level in studied individuals according to their (a) serum cholesterol measures and (b) body mass index. All data are expressed as Mean \pm SE 


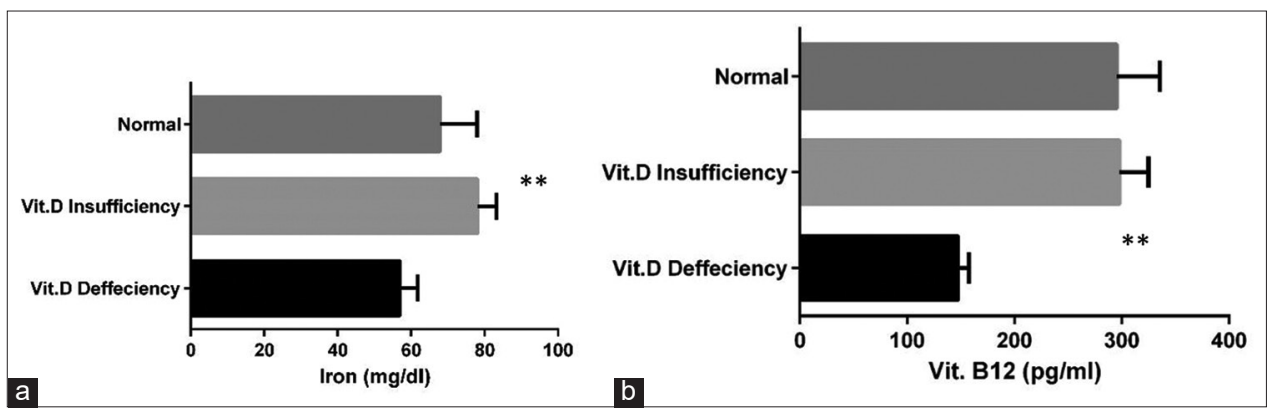

Figure 3: Serum 25(OH) Vitamin D level in studied individuals according to their lifestyle including their (a) Serum Vitamin B12 and (b) Iron level. All data are expressed as Mean \pm SE

in another way, we can also conclude that deficiency in Vitamin D strongly affects the lifestyle of most of the individuals.

Figure 1a clarified that the level of serum $25(\mathrm{OH})$ Vitamin D is significantly higher in persons who sleep more than $8 \mathrm{~h}$ compared to the individuals who sleep $<8 \mathrm{~h}$. The correlation between sleep disorder and VDD has been suggested previously. (Mete et al., 2013) found that when the severity of obstructive sleep apnea syndrome increases, $25(\mathrm{OH}) \mathrm{D}$ deficiency becomes more pronounced. While significant inverse relation was found between the serum $25(\mathrm{OH})$ Vitamin D level and the hours spent with electronic device (Figure 1b), Our analyses are consistent with the hypothesis that low Vitamin D concentration is associated with depression (Anglin et al., 2013). The direct and indirect role of VDD in the regulation of sleep could be related to disturbance of involved hormones (Mergl et al., 2021). Vitamin D receptors and enzymes that control their activation and degradation are expressed in several areas of the brain involved in sleep regulation, Vitamin D is also involved in the pathways of production of melatonin hormone involved in sleep regulation (AlSumaih et al., 2020).

Relation of serum 25(OH) Vitamin D level with BMI and lipids are illustrated in Figure 2. The result very clearly did not show any relation between BMI measures with VDD, but in contrast, the serum 25(OH) Vitamin D level was higher in hyperlipidemic patients (Figure 2a). However, the VDD was higher in obese individuals comparing to the overweight and normal (Wortsman et al., 2000), but the differences were not significant (Figure 2b). The relation sheep between vitamin $\mathrm{D}$ status and obesity existed in previous literature (Pereira-Santos et al., 2015, Wortsman et al., 2000). There are four suggested mechanisms that are most commonly cited within the literature which may explain a low Vitamin D status in obesity: (1) obese individuals have decreased sun exposure compared with their lean counterparts; (2) negative feedback from an increased $1,25(\mathrm{OH}) \mathrm{D}$ concentration in obese individuals

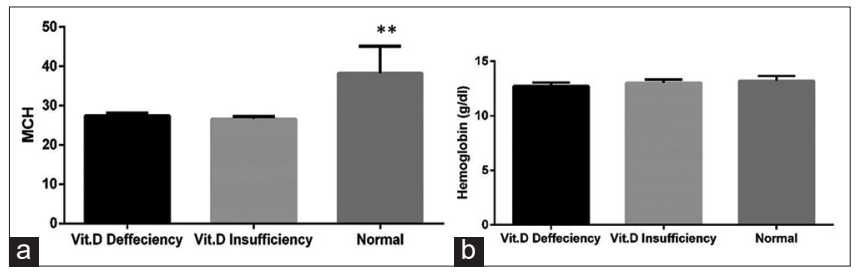

Figure 4: The level of MCH2 (a) and Hemoglobin level (b) in their Vitamin D diagnosis level. The normal individuals have Vitamin D more than $50 \mathrm{ng} / \mathrm{ml}$, While Vitamin $D$ insufficiency represent the subjects with vitamin $D$ between 20 and $50 \mathrm{ng} / \mathrm{ml}$, whereas the deficient patients have Vitamin $D<20 \mathrm{ng} / \mathrm{ml}$. All data are expressed as Mean $\pm \mathrm{SE}$

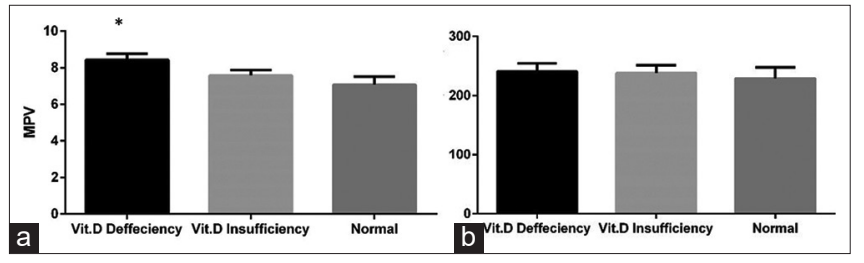

Figure 5: Serum 25(OH) Vitamin D level in studied individuals according to theirlifestyle including their (a) Platelet count and (b) mean platelet volume. All data are expressed as Mean $\pm \mathrm{SE}$

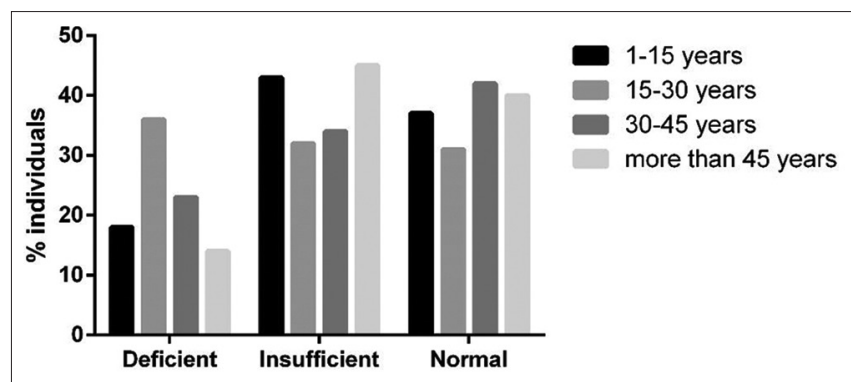

Figure 6: The relation of Age with Vitamin D diagnosis level. The normal individuals have Vitamin $D$ more than $50 \mathrm{ng} / \mathrm{ml}$, While Vitamin D insufficiency represents the subjects with Vitamin D between 20 and $50 \mathrm{ng} / \mathrm{ml}$, whereas the deficient patients have Vitamin $D<20 \mathrm{ng} / \mathrm{ml}$. All data are expressed as percent values

decreases 25(OH)D concentrations; (3) Vitamin $\mathrm{D}$ is sequestered within adipose tissue; (4) lower $25(\mathrm{OH})$ $\mathrm{D}$ concentration is simply due to volumetric dilution (Pourshahidi, 2015). 
Hematological variables recorded significant relation between VDD and tools related to anemia. Figure 3 showed a reduction in Iron status and Vitamin B12 in individuals suffered from VDD, which makes the possibility of having iron-deficiency anemia and megaloblastic anemia more than normal persons (Sim et al., 2010). The association between the prevalence of IDA and VDD has been recorded in previous results(Nur-Eke and Özen, 2020). The mechanism of positive relation between the depletion of vitamin D of iron status is still not well understood. (Lee et al., 2015) suggested that Vitamin D status in Vitamin D children with IDA parents was significantly lower than normal.

The hematological relevant variables revealed nonsignificant differences among the three groups regarding hemoglobin levels (Figure 4b) and platelet count (Figure 5b), while the level of $\mathrm{MCH}$ was significantly reduced in both vitamin deficient and insufficient groups (Figure 4a).

While platelet-related measures indicated a significant induction in MPV in VDD individuals compared to normal persons (Figure 5a). The higher MPV considered as one of the most important risk factors for developing of CVD. Therefore, this finding suggested the relation between CVD and VDD which supports the results obtained by (Culha et al., 2018).

The data analysis revealed that Vitamin D status is varies in different age classes (Figure 6). The age between 15 and 30 years are the most exposed group of individuals who are suffering from VDD. This is because, in this age group, the persons are usually neglecting the healthy lifestyle and less exposed to the sunlight.

\section{CONCLUSION}

This finding revealed that significant relations are exist between between VDD and anemia and cardiovascular variables. The VDD patients have higher CVD risk because of higher MPV and they also posses lower Iron and Vitamin B12 which indicate lower RBC production.

\section{RFERENCES}

Al-Sumaih, I., Johnston, B., Donnelly, M. and O'neill, C. 2020. The relationship between obesity, diabetes, hypertension and vitamin D deficiency among Saudi Arabians aged 15 and over: results from the Saudi health interview survey. BMC Endocr. Disord. 20(1): 81.

Anglin, R.E., Samaan, Z., Walter, S.D. and Mcdonald, S.D. 2013. Vitamin $\mathrm{D}$ deficiency and depression in adults: Systematic review and meta-analysis. Br. J. Psychiatr. 202: 100-107.

Atkinson, M.A., Melamed, M.L., Kumar, J., Roy, C.N., Miller, E.R. $3^{\text {rd }}$.,
Furth, S.L. and Fadrowski, J.J. 2014. Vitamin D, race, and risk for anemia in children. J. Pediatr. 164(1): 153-158. e1.

Bell, N.H., Epstein, S., Greene, A., Shary, J., Oexmann, M.J. and Shaw, S. 1985. Evidence for alteration of the vitamin D-endocrine system in obese subjects. J. Clin. Investig. 76(1): 370-373.

Calvo, M.S., Whiting, S.J. and Barton, C.N. 2005. Vitamin D intake: A global perspective of current status. J. Nutr. 135(2): 310-316.

Culha, M.G., Atalay, H.A., Canat, H.L., Alkan, I., Ozbir, S., Can, O. and Otunctemur, A. 2018. The relationship between erectile dysfunction severity, mean platelet volume and Vitamin D levels. Aging Male. 23(3): 173-178.

Golbahar, J., Altayab, D., Carreon, E. and Darwish, A. 2013. Association of Vitamin $D$ deficiency and hyperparathyroidism with anemia: A cross-sectional study. J. Blood Med. 4: 123.

Hirani, V., Cumming, R.G., Blyth, F., Naganathan, V., Le Couteur, D.G., Waite, L.M., Handelsman, D.J. and Seibel, M.J. 2015. Cross-sectional and longitudinal associations between the active Vitamin D metabolite $(1,25$ dihydroxyvitamin D) and haemoglobin levels in older Australian men: The concord health and ageing in men project. Age. 37(1): 8.

Holick, M.F. 2007. Vitamin D deficiency. N. Engl. J. Med. 357(3): 266-281.

Jaumdally, R.J., Varma, C., Blann, A.D., Macfadyen, R.J. and Lip, G.Y. 2007. Platelet activation in coronary artery disease: Intracardiac vs peripheral venous levels and the effects of angioplasty. Chest. 132(5): 1532-1539.

Lee, J.A., Hwang, J.S., Hwang, I.T., Kim, D.H., Seo, J.H. and Lim, J.S. 2015. Low Vitamin D levels are associated with both iron deficiency and anemia in children and adolescents. Pediatr. Hematol. Oncol. 32(2): 99-108.

Mergl, R., Dogan-Sander, E., Willenberg, A., Wirkner, K., Kratzsch, J., Riedel-Heller, S., Allgaier, A.K., Hegerl, U. and Sander, C. 2021. The effect of depressive symptomatology on the association of Vitamin D and sleep. BMC Psychiatry. 21(1): 1-10.

Mete, T., Yalcin, Y., Berker, D., Ciftci, B., Guven, S., Topaloglu, O., Yavuz, H. and Guler, S. 2013. Obstructive sleep apnea syndrome and its association with Vitamin D deficiency. J. Endocrinol. Investig. 36(9): 681-685.

Nur-Eke, R. and Özen, M. 2020. The relationship between Vitamin $\mathrm{D}$ levels and iron deficiency and anemia in adults applied for periodic medical examination. Clin. Lab. 66(6): 1019-1026.

Oren, Y., Shapira, Y., Agmon-Levin, N., Kivity, S., Zafrir, Y., Altman, A., Lerner, A. and Shoenfeld, Y. 2010. Vitamin D insufficiency in a sunny environment: $A$ demographic and seasonal analysis. Israel Med. Assoc. J. 12(12): 751.

Parikh, S.J., Edelman, M., Uwaifo, G.I., Freedman, R.J., SemegaJanneh, M., Reynolds, J. and Yanovski, J.A. 2004. The relationship between obesity and serum 1, 25-dihydroxy Vitamin $\mathrm{D}$ concentrations in healthy adults. J. Clin. Endocrinol. Metab. 89(3): 1196-1199.

Pereira-Santos, M., Costa, P.R.D., Assis, A.M.O., Santos, C.A.D. and Santos, D.B.D. 2015. Obesity and Vitamin D deficiency: A systematic review and meta-analysis. Obes. Rev. 16(4): 341349.

Pourshahidi, L.K. 2015. Vitamin D and obesity: Current perspectives and future directions. Proc. Nutr. Soc. 74(2): 115-124.

Riccio, E., Sabbatini, M., Bruzzese, D., Capuano, I., Migliaccio, S., Andreucci, M. and Pisani, A. 2015. Effect of paricalcitol vs calcitriol on hemoglobin levels in chronic kidney disease patients: A randomized trial. PLoS One. 10(3): e0118174.

Rondina, M.T., Weyrich, A.S. and Zimmerman, G.A. 2013. Platelets as cellular effectors of inflammation in vascular diseases. Circ. 
Res. 112(11): 1506-1519.

Santoro, D., Caccamo, D., Lucisano, S., Buemi, M., Sebekova, K., Teta, D. and De Nicola, L. 2015. Interplay of Vitamin D, erythropoiesis, and the renin-angiotensin system. Biomed Res. Int. 2015;2015:145828.

Semple, J.W. and Freedman, J. 2010. Platelets and innate immunity. Cell. Mol. Life Sci. 67(4): 499-511.

Sim, J.J., Lac, P.T., Liu, I.L.A., Meguerditchian, S.O., Kumar, V.A., Kujubu, D.A. and Rasgon, S.A. 2010. Vitamin D deficiency and anemia: A cross-sectional study. Ann. Hematol. 89(5): 447-452.

Sooragonda, B., Bhadada, S.K., Shah, V.N., Malhotra, P., Ahluwalia, J. and Sachdeva, N. 2015. Effect of Vitamin D replacement on hemoglobin concentration in subjects with concurrent iron- deficiency anemia and Vitamin D deficiency: A randomized, single-blinded, placebo-controlled trial. Acta Haematol. 133(1): 31-35.

Valettas, N. and Herrmann, H.C. 2003. The role of platelets and platelet inhibition in acute myocardial infarction. Coron. Artery Dis. 14(5): 357-363.

Wang, Y., Andrews, M., Yang, Y., Lang, S., Jin, J., CameronVendrig, A., Zhu, G., Reheman, A. and Ni, H. 2012. Platelets in thrombosis and hemostasis: Old topic with new mechanisms. Cardiovasc. Haematol. Disord. Drug Targets. 12(2): 126-132.

Wortsman, J., Matsuoka, L.Y., Chen, T.C., Lu, Z. and Holick, M.F. 2000. Decreased bioavailability of Vitamin D in obesity. Am. J. Clin. Nutr. 72(3): 690-693. 